\title{
Voltage-Dependent R-Type Calcium Channel Subunit Alpha-1E
}

National Cancer Institute

\section{Source}

National Cancer Institute. Voltage-Dependent R-Type Calcium Channel Subunit Alpha-1E. NCI Thesaurus. Code C150182.

Voltage-dependent R-type calcium channel subunit alpha-1E (2313 aa, $262 \mathrm{kDa})$ is encoded by the human CACNA1E gene. This protein is involved in voltage-dependent calcium transport. 